\title{
Open space suitability analysis for emergency shelter after an earthquake
}

\author{
J. Anhorn ${ }^{1,3}$ and B. Khazai ${ }^{2,3}$ \\ ${ }^{1}$ South Asia Institute (SAI), Heidelberg University, INF 330, 69120 Heidelberg, Germany \\ ${ }^{2}$ Center for Disaster Management and Risk Reduction Technology (CEDIM), Karlsruhe Institute of Technology, \\ Hertzstrasse 16, 76187, Karlsruhe, Germany \\ ${ }^{3}$ HEiKA - Heidelberg Karlsruhe Research Partnership, Heidelberg University and Karlsruhe \\ Institute of Technology, Heidelberg and Karlsruhe, Germany
}

Correspondence to: J. Anhorn (anhorn@sai.uni-heidelberg.de)

Received: 2 April 2014 - Published in Nat. Hazards Earth Syst. Sci. Discuss.: 11 June 2014

Revised: 14 October 2014 - Accepted: 8 March 2015 - Published: 10 April 2015

\begin{abstract}
In an emergency situation shelter space is crucial for people affected by natural hazards. Emergency planners in disaster relief and mass care can greatly benefit from a sound methodology that identifies suitable shelter areas and sites where shelter services need to be improved. A methodology to rank suitability of open spaces for contingency planning and placement of shelter in the immediate aftermath of a disaster is introduced. The Open Space Suitability Index uses the combination of two different measures: a qualitative evaluation criterion for the suitability and manageability of open spaces to be used as shelter sites and another quantitative criterion using a capacitated accessibility analysis based on network analysis. For the qualitative assessment implementation issues, environmental considerations and basic utility supply are the main categories to rank candidate shelter sites. A geographic information system is used to reveal spatial patterns of shelter demand. Advantages and limitations of this method are discussed on the basis of an earthquake hazard case study in the Kathmandu Metropolitan City. According to the results, out of 410 open spaces under investigation, $12.2 \%$ have to be considered not suitable (Category D and E) while $10.7 \%$ are Category A and $17.6 \%$ are Category B. Almost two-thirds $(59.55 \%)$ are fairly suitable (Category C).
\end{abstract}

\section{Introduction}

As the impacts of natural disasters continue to increase around the world, experts agree that post-event response has to become more efficient and draw on science (Balcik et al., 2010; Bharosa et al., 2010; McEntire, 2007; Rawls and Turnquist, 2010). This becomes visible, for example, through the formulation of the United Nations International Strategy for Disaster Reduction (UN ISDR) in 2000. Pre-disaster planning as well as risk mitigation measures have gained interest in both scientific and practitioner communities. As the primary international agreement for disaster reduction, the Hyogo Framework of Action prioritizes "strengthening preparedness for response" as one of its five priorities of action identified for 2005 to 2015 (UN ISDR and UN OCHA, 2008, p. 1).

One important concern of strategies to improve preparedness for response is the identification and provision of suitable areas for emergency shelter before disasters unfold (Chandler, 2007; Chien et al., 2002; Donohou, 2012; Perry, 1979; Perry and Green, 1982; Tai et al., 2010). Especially in urban contexts the availability of such areas is often limited and there is increasing demand for risk-sensitive land use planning which are often lacking (e.g., Global Communities, 2012).

Shelter needs can be divided, according to the time elapsed from the onset of the disaster event, into emergency shelter, temporary shelter, temporary housing, and permanent housing (Chou et al., 2013; Donohou, 2012; Félix et al., 2013; Johnson, 2007, 2009; Lizarralde et al., 2009; Quarantelli, 
1995). The timeline for transitioning from these different phases of shelter needs - for example from emergency shelter to temporary shelter - is often variable; however, the underlying sequential process seldom becomes reality (Johnson, 2007; Ritchie and Tierney, 2011). Earthquakes confront emergency managers with special challenges due to their rapid onset and relatively short duration. Furthermore, as earthquakes are inherently unpredictable, there is usually no lead time for preemptive evacuation, which results in emergency shelter placement becoming mostly a post-event issue (e.g., Wright and Johnson, 2010). Pre-event planning and preparedness for emergency shelter placement is thus critical for ensuring a coordinated response during the complex and changing risk contexts after a large earthquake.

Planning for emergency shelter placement draws on standards, criteria, and guidelines developed for emergency managers and humanitarian organizations which have been based mostly on post-disaster assessments (e.g., Da Silva, 2007; SPHERE Project, 2011; UNDRO, 1982; UN OCHA et al., 2010). For example, the SPHERE Project provides minimum standards and general guidance for use in any of several response scenarios and includes provisions for strategic planning, settlement planning, covering living space, construction, and environmental impact for shelter and settlements (SPHERE Project, 2011). While the minimum standards provide the basis for developing an emergency shelter placement plan, optimal siting and accessibility of shelter sites based on shelter needs from comprehensive risk assessments are also required (Indriasari et al., 2010). There is still a lack of combined approaches to investigate demand for public emergency shelter sites with their suitability and accessibility incorporating capacity constraints of (candidate) shelter sites.

In this paper we propose a methodology that examines the capacity of open spaces to be used as public emergency shelter sites, which takes into account both how well a site meets demand for public shelter as well as the level of accessibility of the site using a deterministic earthquake risk assessment. Alongside the quantitative capacity analysis, a set of qualitative suitability criteria (SI) are proposed for open spaces to be used as temporary shelter sites during an earthquake emergency. The combined Open Space Suitability Index (OSSI) will rank candidate sites according to their accessibility, taking into consideration the available capacity and also their suitability for earthquake shelter purposes based on expert knowledge.

We showcase this methodology on officially identified open spaces by the National Society for Earthquake Technology (NSET), Nepal, and the International Organization for Migration (IOM) within Kathmandu Metropolitan City (KMC) using the combination of two different measures: a qualitative evaluation criterion for the suitability and manageability and a second quantitative criterion using a capacitated accessibility analysis based on both an earthquake risk analysis and a network analysis based on a geographic information system (GIS). We thereby assume a "worst-case earthquake scenario" in which shelter placement is exclusively based on open spaces, as very few buildings, such as schools and shopping malls, can be considered stable enough to be used for shelter purposes.

The paper is structured as follows: first, the rationale of a combined method to investigate capacity-based suitability of shelter sites is given. As such, existing methods to calculate displaced and shelter-seeking populations resulting from earthquakes as the fundamental prerequisite of such a methodology are reviewed. Second, a set of categories to characterize site suitability based on qualitative indicators is proposed. Furthermore, a methodology to derive capacitated accessibility using spatial network analysis as a key measure to evaluate further shelter needs in a spatial context is introduced. Third, the combined OSSI is outlined. Fourth, the proposed methodology for open space suitability analysis for emergency shelters is applied to our case study in KMC. The final sections reflect on the results from the case study and discuss limitations and the transferability of the method to other hazards.

\section{Shelter suitability}

\subsection{Shelter need}

The initial estimation of the potential number of displaced population after a disaster is a major step in emergency management and a prerequisite for calculating temporary shelter demand. While many casualty estimation methodologies exist in earthquake engineering that provide estimates of both injuries and fatalities by relating the intensity of the earthquake and/or damaged buildings to casualty potential (Coburn and Spence, 2006; FEMA, 1999, 2011; Samardjieva and Badal, 2002), methods for estimating displaced population and population in need of shelter are far fewer. Examining data from 457 historic earthquakes from 1900 to 2012 in the CATDAT damaging earthquake database (Daniell et al., 2011; Khazai et al., 2014) shows that while a general linear trend on logarithmic scale is observable between damaged buildings after an earthquake and the number of homeless people, for many events there are scalar differences from this trend that not only depend on external factors like building damage, loss of utilities, and weather conditions but also on internal socioeconomic and individual factors such as safety concerns or fear of aftershocks (Khazai et al., 2014).

Most earthquake loss estimation (ELE) software for calculating shelter needs is based on the HAZUS methodology (ABAG, 1996; Harrald and al Hajj, 1992) and accounts for several variables on the census track level influencing the tendency to seek short-term shelter, including income, ethnicity, age, and ownership (FEMA, 2011). Chou (2013) proposes the use of three variables determining higher tendency to seek shelter out of all displaced people affected by an earthquake, namely low household income, rented housing tenure, 
and belonging to either the youngest ( $<16$ years) or the oldest ( $>65$ years) age group. Chien et al. (2002) use contextualized weights explored in a shelter survey after the Chi-Chi Earthquake in Taiwan to revise the HAZUS default values.

Shelter needs are mostly calculated directly as a function of structural damage to buildings not taking into account household decision making or social and demographic factors, which is considered a deficit by some authors (Khazai et al., 2011, 2014; Tierney et al., 2001). Besides building damage, social factors have emerged as crucial in forming the decision to seek shelter or not on a household and individual level (Chang et al., 2009; Chou et al., 2013; Khazai et al., 2014). Riad et al. (1999) state that besides risk characteristics, territorial tendencies (house ownership) and personal characteristics - like social support, education, financial wellbeing - are influencing people's decision to seek shelter. Additionally, they state that "social influences on evacuation behavior may vary according to the resident's network size and ethnicity" (Riad et al., 1999, p. 921). Another important determinant of the number of people seeking shelter was found inter alia by Wright and Johnston (2010) and Chang and Chamberlin (2003) to be the loss of lifelines. Interactions between the physical damage state of buildings and the combined residual service level in the utility networks have been considered in a system approach to assess the habitability of buildings from which the number of displaced persons can be computed (Cavalieri et al., 2012; Khazai et al., 2013). The rationale for this is that people are likely to seek refuge in a public shelter if they are cut off from basic necessities such as water supply or electricity, even if buildings are otherwise intact. For example, during the L'Aquila earthquake of 2009, shelter seekers originated not only from non-usable (collapsed or cut off from lifelines) buildings but also from partly damaged and non-damaged buildings (up to $54 \%$ ) (Khazai et al., 2012). Furthermore, risk perception and access to resources are identified as influential factors by Chang et al. (2009) and Chakraborty et al. (2005). Upreti $(2009$, p. 52) shows that $87 \%$ of Kathmandu's citizens do not believe an earthquake is going to happen during their lifetime even though they are aware of the possibility. This shows that most people will be hit unprepared should a major disaster occur in the near future.

\subsection{Suitability}

The SPHERE shelter and settlement standard for covered living space provides a guideline for emergency managers to evaluate or plan for immediate, short-, and long-term shelter (SPHERE Project, 2011). It recommends an area in excess of $3.5 \mathrm{~m}^{2}$ per person to meet requirements of typical household activities. The overall surface area per person, including communal space for cooking, roads and footpaths, educational facilities, administration etc., within temporary communal settlements should be $45 \mathrm{~m}^{2}$. Besides surface area, special consideration is given to water, sanita- tion, and health, community infrastructure, security, and secondary risks (SPHERE Project, 2011, p. 247 ff.). All in all, the standards aim to use strategic settlement planning to enable "safe and secure use of accommodation and essential services by the affected population" (SPHERE Project, 2011, p. 254). Especially in densely populated urban areas, the shelter demand can exceed the supply in close vicinity of the affected population if these standards are enforced rigorously. Limited available space may urge adjustments on the applied average shelter space per person.

Suitability of open spaces for shelter purposes depends on the perspective from which it is evaluated. Da Silva stresses the need to consider the "shelter occupant's perspective" (Da Silva, 2007, p. 25) when shelter site quality is evaluated. Emergency planners and affected population may have a differing perception of relevant considerations in the immediate aftermath of an earthquake. For example, emergency planners evaluate shelter sites with respect to a longer time frame. Limitations for implementation, existing secondary hazards as well as future construction plans play a predominant role. A shelter-seeking person, however, focuses on accessibility and space availability when looking for an immediate emergency shelter site. Hence sheltering in the close vicinity of one's own plot or house may be of greater importance than mid-term perspectives.

The qualitative suitability indicators used for the OSSI are described in the following section and are mostly inferred from the SPHERE standards. As a matter of course other relevant indicators should be added if applicable (e.g., different local context, data constraints, or expanding to other hazards). The selection and weighting of indicators remains the greatest difficulty and needs to incorporate expert judgment. The weighting of categories and indicators was done in a participatory way in four consecutive expert group discussions involving emergency management researchers from NSET and from the Center for Disaster Management and Risk Reduction Technology (CEDIM) in Karlsruhe, Germany. The rationale behind the choice of individual factors often lies in the stakeholders' or experts' experiences and available data. Consequently, it is important to state concisely the scope and objectives of such an index. The methodology we propose focuses on suitability for immediate emergency shelter, with weighting of indicators and categories applicable to this context. The following three core categories have therefore been identified to explore suitability of open spaces in an urban context for immediate shelter after an earthquake: implementation issues, environmental considerations, and basic utilities supply (Table 1).

The category implementation issues consists of ownership, existing use, and future plans. Generally, publicly (governmental) owned spaces should be preferred, as these can be managed easier than privately owned open spaces (cf. FEMA, 2007). Another indicator is the current type of use. A playground or a park for example is best suited for shelter, since their existing type of use does not hamper camp 
Table 1. Overview of suitability categories and indicator criteria for immediate shelter sites.

\begin{tabular}{|c|c|c|c|c|}
\hline Category & Weight & Indicator & Score & Explanation \\
\hline \multirow[t]{3}{*}{$\begin{array}{l}\text { Implementation } \\
\text { issues }\end{array}$} & 0.1 & Ownership & $\begin{array}{r}1 \\
0.7\end{array}$ & $\begin{array}{l}\text { public (governmental, community, religious, institutional, educational) } \\
\text { private }\end{array}$ \\
\hline & 0.06 & Future plan & $\begin{array}{r}1 \\
0.5 \\
0\end{array}$ & $\begin{array}{l}\text { no plan, planned park, planned garden, planned } \\
\text { playground, or long-term structure plan } \\
\text { short-term structure plan } \\
\text { under partial or full construction }\end{array}$ \\
\hline & 0.2 & Existing use & $\begin{array}{r}1 \\
0.7 \\
0.5 \\
0.4 \\
0.1\end{array}$ & $\begin{array}{l}\text { non-used, park, garden, or playground } \\
\text { religious } \\
\text { agricultural or institutional } \\
\text { educational } \\
\text { dumping site }\end{array}$ \\
\hline \multirow[t]{2}{*}{$\begin{array}{l}\text { Environmental } \\
\text { considerations }\end{array}$} & 0.18 & $\begin{array}{l}\text { Secondary } \\
\text { hazards }\end{array}$ & $\begin{array}{r}1 \\
0.7 \\
0.5 \\
0.4 \\
0.2\end{array}$ & $\begin{array}{l}\text { no secondary hazard } \\
\text { fire or flood hazard } \\
\text { fire and landslide hazard } \\
\text { fire and flood hazard } \\
\text { fire and landslide and flood hazard }\end{array}$ \\
\hline & 0.1 & $\begin{array}{l}\text { Pollution } \\
\text { issues }\end{array}$ & $\begin{array}{l}1 \\
0.9 \\
0.8 \\
0.5 \\
0.4 \\
0.3 \\
0.2\end{array}$ & $\begin{array}{l}\text { Category } 0: \text { no pollution } \\
\text { Category } 1 \text { : noise pollution or air pollution } \\
\text { Category 2: river pollution } \\
\text { Category } 3 \text { : urban waste pollution } \\
\text { Category } 1 \text { and Category } 3 \\
\text { Category } 2 \text { and Category } 3 \\
\text { Category } 1 \text {, Category } 2 \text {, and Category } 3\end{array}$ \\
\hline \multirow[t]{3}{*}{$\begin{array}{l}\text { Basic } \\
\text { utilities } \\
\text { supply }\end{array}$} & 0.1 & Electricity & $\begin{array}{r}1 \\
0.9 \\
0.7 \\
0.1\end{array}$ & $\begin{array}{l}\text { distribution line and generator(s) or alternative source } \\
\text { generator(s) or alternative source } \\
\text { distribution line } \\
\text { no electricity available }\end{array}$ \\
\hline & 0.11 & $\begin{array}{l}\text { Water } \\
\text { supply }\end{array}$ & $\begin{array}{r}1 \\
0.8 \\
0.7 \\
0.6 \\
0.5 \\
0.4 \\
0.2 \\
0\end{array}$ & $\begin{array}{l}\text { some type of source and tank and piped water } \\
\text { some type of source and tank } \\
\text { some type of source and piped water } \\
\text { some type of source (natural source, ground water, or deep boring) } \\
\text { tank and piped water } \\
\text { tank } \\
\text { piped water } \\
\text { no water supply available }\end{array}$ \\
\hline & 0.15 & $\begin{array}{l}\text { Nearness to } \\
\text { critical } \\
\text { facilities }\end{array}$ & $\begin{array}{r}0.9 \\
0.8 \\
0.6 \\
0.4 \\
0\end{array}$ & $\begin{array}{l}\text { hospital(s) within less than } 1 \mathrm{~km} \text { distance } \\
\text { hospital(s) within more than } 1 \mathrm{~km} \text { distance but less than } 2 \mathrm{~km} \\
\text { hospital(s) within more than } 2 \mathrm{~km} \text { distance but less than } 3 \mathrm{~km} \\
\text { hospital(s) within more than } 3 \mathrm{~km} \text { distance } \\
\text { unknown distance to next hospital }\end{array}$ \\
\hline
\end{tabular}

erection. If the space has an institutional or educational function it should not be prioritized for immediate shelter in order to not delay the resumption of daily activities and not to endanger people due to potentially unstable building conditions (c.f. SPHERE Project, 2011). The future planning indicator gives a last indication regarding usage complications. Some sites have existing long- or even short-term plans in place, are already under partial or complete construction, and should thus not be preferred. During the site visits, some of the places turned out to be used as dumping sites and such areas were considered the least suitable ones. The rationale behind this category indicates possible restrictions in access or continuing use.

As an environmental consideration we include pollution and secondary hazard criteria. Air, water, or waste pollution needs to be taken into account. Only shelter sites with a clean air supply (i.e., not in areas with high air pollution discharge due to debris or road traffic) and cleared grounds (i.e., no dumping areas) should be chosen as shelter sites. Possible shelter sites should not include areas prone to other haz- 
ards (floods, landslides, etc.). Additionally, secondary hazards like potential fire eruption from nearby hazardous materials (e.g., gas and petrol sellers) need to be taken into account and avoided in the choice of a suitable shelter area (FEMA, 2007; Tai et al., 2010).

Access to basic utility supply systems and critical infrastructure such as hospitals need to be considered as part of site suitability. Sufficient and continuous supply with basic utilities such as water and electricity are crucial immediately after a disastrous event (Chang et al., 2009; Chu and Su, 2011; Daley et al., 2001; FEMA, 2011). The proximity to medical services has also found wide acceptance as an important factor (FEMA, 2007; SPHERE Project, 2011). Hospitals are particularly important due to high numbers of injuries incurring during an earthquake and to prevent high numbers of post-event "fade-away" people (Coburn et al., 1992).

\subsection{Accessibility}

People seeking shelter rely on some sort of existing and suitable network (roads) to access available shelter areas within a certain time (Tai et al., 2010). Kongsomsaksakul et al. (2005) use a two-level mathematical representation to show authorities' selections of best-suited evacuation sites on the one hand and evacuees' decisions on the escape route to that determined site on the other hand. The number of people seeking shelter and the decision to access a particular shelter site relies on several factors ranging from socio-cultural and economic factors to physical constraints like road network accessibility after the event and availability of motorized or non-motorized vehicles.

Many studies focus on transportation issues in terms of time constraints to reach evacuation sites during preemptive evacuations (Cova and Church, 1997; Cova and Johnson, 2002; Kar and Hodgson, 2008). Others focus on different variables determining the "evacuation assistance needs" (Chakraborty et al., 2005, p. 23) based on social vulnerability and earthquake risk patterns.

Kar and Hodgson (2008) use a GIS-based suitability model to investigate the number and location of predefined shelter areas for preemptive hurricane evacuation. They identify a set of factors from official and unofficial guidelines and determine the suitability of shelter sites using weighted linear combination and a pass/fail screening on raster basis. The shelter sites used in their study are mostly public multipurpose assembly facilities, like cultural or civic centers, and healthcare facilities. Factors included are proximity measures and vulnerability profiles of the population (percentage of children, elders, minorities, and low-income households). Gall (2004) highlights the importance of shelter sites for humanitarian assistance in terms of relief good distribution. The model follows some basic assumptions that are only applicable in rural areas where transportation friction can be modeled as a result of land cover and distance only.
Indriasari et al. (2010) use a similar approach to identify the optimal siting of emergency facilities like fire brigades or hospitals. They argue that maximum coverage is more applicable for identifying suitable emergency facilities among a larger set of candidate sites than methods minimizing the distance between demand and supply. In general, the main difference between the approaches is the spatial domain: Gall (2004) uses a raster-based model with continuous friction data, while Indriasari et al. (2010, p. 2014) apply the facility location problem on a street network "taking into account the road access, barriers, and road network attributes". All these methods focus on emergency facility location problems for preemptive evacuation, which differ from the challenges the shelter-seeking population faces in the aftermath of an earthquake.

Network analysis has been proven to be a valuable tool for analyzing the strengths and weaknesses of manifold types of spatial and non-spatial networks (cf. Crucitti et al., 2006). With its theoretical foundation in graph theory, road networks are defined as elements of nodes and edges, either using street segments as edges (primal representation) or as nodes (dual representation) (Porta et al., 2006a, b). The most important feature and analytic strength of network analysis is the inherent importance of relational topological information. Results often comprise of the summed costs (e.g., time, length) or turns of nodes between predefined sets of origins (demand) and destinations (supply). Network analysis, for example, allows calculating least-cost distances in terms of travel time or distance using impedance values for different node types from/to destinations. Other measures are service areas to determine the extent of business relations or run calculations for logistic fleet management or manifold facility location problems (e.g., Toregas et al., 1971). The usability of network analysis in the emergency context has been shown on different examples, like optimal siting of emergency facilities (Indriasari et al., 2010) and emergency routing services on near-real-time basis (Neis et al., 2010; Weiser and Zipf, 2007). Differences in accessibility constraints during or after extreme events affecting road networks can be investigated using, for example, volunteered geographic information (VGI) (Neis and Zielstra, 2014).

With their Urban Network Analysis toolbox, Sevtsuk and Mekonnen (2012) introduce an additional level of analysis to the traditional calculation of network centrality: the building level. Previous studies focused solely on the capabilities and centrality measures of the network itself (nodes and edges), ignoring individual elements along the edges. They promote adding buildings as supplementary nodes and establishing links between single buildings and the adjacent (closest) road network.

We use the Maximize Capacitated Coverage analysis (implemented in ESRIs ArcGIS ${ }^{\mathrm{TM}} 10.1$ Network Analyst) to determine the maximum coverage of selected sites, taking into consideration network impedance, building weight, and shelter capacity. The method uses Dijkstra's algorithm for finding 


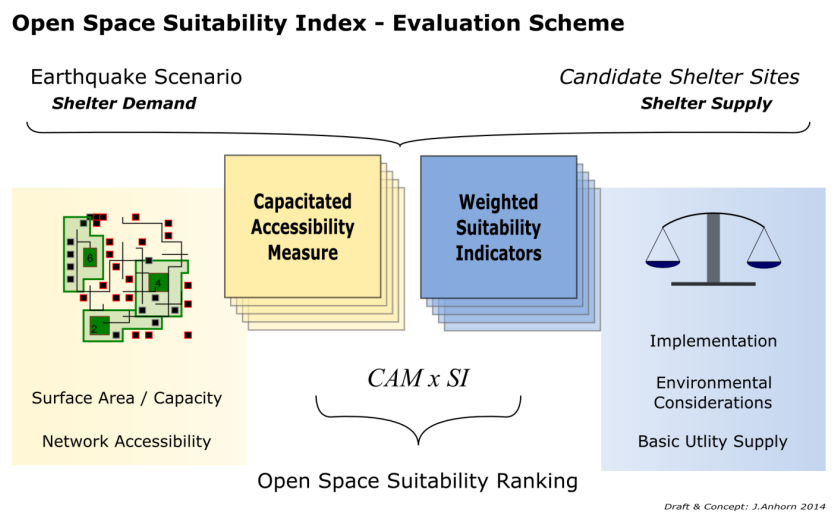

Figure 1. Open Space Suitability Index (OSSI) evaluation scheme.

the shortest paths and solves the location-allocation problem by choosing a subset of facilities (candidate shelter sites) such that the sum of the weighted distances from each demand point (with a certain weight) to the closest shelter site is minimized (ESRI, 2013). Thus it assigns each demand point (building) to the closest candidate shelter facility (supply) according to the number of people seeking shelter (weight), taking into consideration the overall capacity and the total length network distance of all buildings. Capacity of candidate shelter sites is deduced using existing standards for covered living space as described earlier. The number of people seeking shelter is used as the weighting factor for each building.

\section{Open Space Suitability Index}

The objective of this study is to model shelter site suitability considering road network accessibility, capacity, and suitability of shelter. We focus on immediate shelter placement with a time frame up to several days following an earthquake. The final suitability index OSSI consists of two factors: first an expert-based weighting procedure of SI and second a GISbased accessibility and capacity measure $\left(\mathrm{CAM}_{\mathrm{OS}}\right)$. Figure 1 shows the evaluation scheme applied. It is calculated using the following equations:

$$
\begin{aligned}
\mathrm{OSSI}_{\mathrm{OS}} & =\sum_{n=1}^{n}\left(W_{i} \times I_{i}+W_{i+1} \times I_{i+1}+\ldots+W_{n} \times I_{n}\right) \\
& \times \mathrm{CAM}_{\mathrm{OS}}, \\
& \mathrm{CAM}_{\mathrm{OS}}=\frac{\text { POPserved }_{\mathrm{OS}}}{\text { POP }_{\mathrm{OS}}}
\end{aligned}
$$

where $I_{i}$ is the suitability indicator scores and $W_{i}$ is the respective weight for each indicator. $\mathrm{CAM}_{O S}$ is calculated as the ratio between the total shelter-seeking population within a $1 \mathrm{~km}$ service area of each candidate shelter site $\left(\mathrm{POP}_{\mathrm{OS}}\right)$ derived from an earthquake risk assessment and the people accommodated within the same spatial unit according to the Maximize Capacitated Coverage analysis result
(POPserved $O$ ). The $\mathrm{CAM}_{\mathrm{OS}}$ determines the "pressure" on each candidate site to be overcrowded due to the surrounding undersupply. It shows a spatial representation of shelterdemanding population that can be served with appropriate shelter space. The $1 \mathrm{~km}$ cutoff value is used as a standardization factor and determined by the overall size of the used network. It helps to identify hot spots of unserved populated areas within the urban environment. Therefore, the optimal facility location problem is modified to address existing suitability constraints and limited capacity of shelter areas.

\section{Case study Kathmandu Metropolitan City}

The territory of Nepal spans about one-third of the length of the Himalayan arc, leading to a long history of devastating earthquakes in Nepal. Over the last century, the Himalayan arc has experienced four earthquakes with magnitude around 8.5 in 1897, 1905, 1934, and 1950. As one of the most devastating earthquakes in the recent past, the 1934 Bihar earthquake of magnitude $M_{\mathrm{w}} 8.3$ caused the collapse of $20 \%$ of all buildings in the Kathmandu Valley; another $40 \%$ were severely damaged (EMI, 2010; JICA and MoHA, 2002). Today, the total population in the Kathmandu Valley is 8-fold what it was in 1934; its density has quadrupled. Expansion took place without political supervision, despite various efforts to enforce spatial planning (Gutschow and Kreutzmann, 2012; Thapa et al., 2008; Thapa and Murayama, 2009). As the political and cultural capital of Nepal, KMC within the Kathmandu Valley is particularly at risk. With its fertile land the valley has attracted many people living off farming (Gutschow and Kreutzmann, 2012). However, with rapid growth of urban centers much of the open land has vanished in favor of built-up living space in the recent decades (Haack and Rafter, 2006). Today, with an average annual growth rate of $4.59 \%$ between 2000 and 2005, Kathmandu is one of the fastest-growing city in the world, facing high earthquake risk (UN DESA, 2012). Owing to this unimpeded urban growth, an earthquake of similar magnitude as the Bihar earthquake would result in significantly higher losses in the form of casualties and physical destruction (Dixit et al., 2000; Guragain et al., 2008). Experts estimate that at least 1 million homeless people in need of immediate assistance can be expected and all routes into and out of the Kathmandu Valley will be blocked for weeks if not months (NRRC, 2013). Assuming this holds true, all emergency services need to be supplied from within the valley - without external help.

The above-mentioned 2-fold suitability analysis of open space shelter sites is implemented in a case study for the KMC. The open spaces used in the analysis (Fig. 2) are based on 887 open spaces identified by NSET as potential sites for emergency purposes, out of which 410 are located within KMC (NSET, 2010, 2012). In the assessment, most publicly owned cleared areas and smaller open spaces or courtyards were included. The qualitative suitability information 


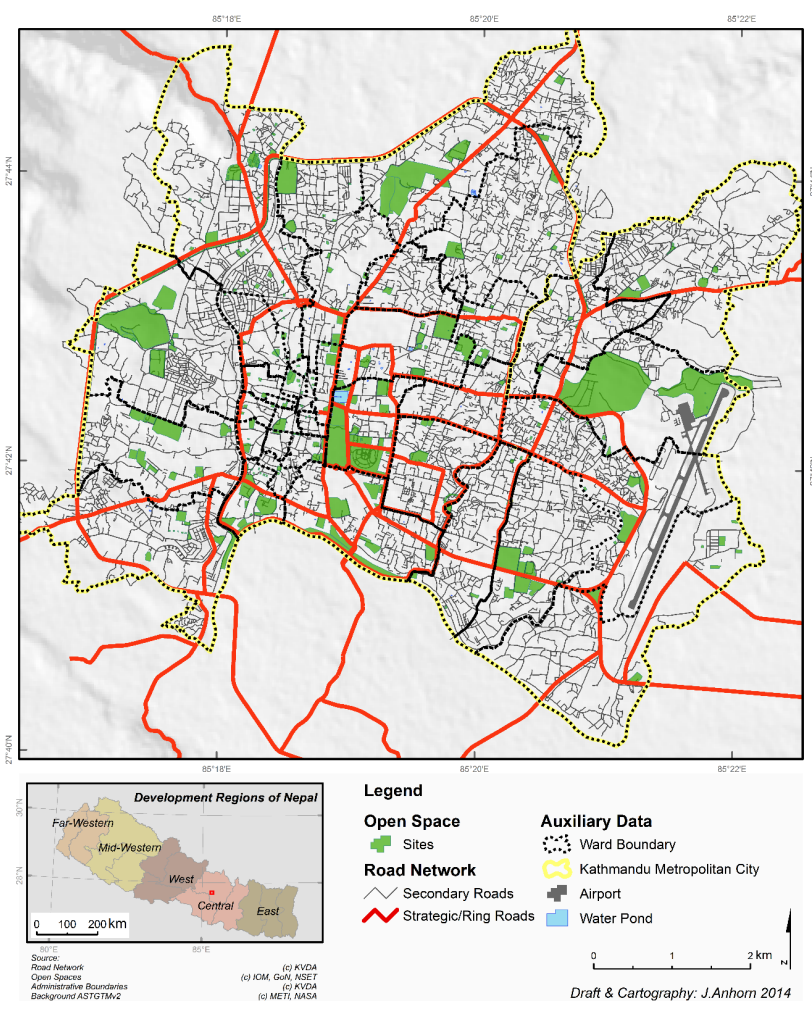

Figure 2. Distribution of open spaces in Kathmandu Metropolitan City.

was obtained using structured data entry forms. The criteria for the identification can be found in the "Shelter Response Strategy and Plan for Earthquake Disasters for Kathmandu Valley, Nepal" (NSET, 2010, 2012). Other places (like private areas, agricultural land inside the city boundaries) are not considered. Additionally, IOM and the Ministry of Home Affairs jointly identified 83 open spaces for medium-term post-disaster needs including larger facilities for camp establishing (IOM and GoN, 2012). In their assessment, only publicly owned sites and areas controlled by commercial entities with which the government could enter a formal contingency agreement were considered. The qualitative data available from both data sets were combined and converted using the weighting scheme formulated in four consecutive expert round-table discussions (Table 1). They form the basis for the qualitative part of the OSSI. The available area of $2285 \mathrm{~km}^{2}$ supplies a maximum of 253900 persons as shelter, applying a standard of $9 \mathrm{~m}^{2}$ per person.

The Japan International Cooperation Agency (JICA) "Study on Earthquake Disaster Mitigation for Kathmandu Valley, Nepal"(SEDM) has been used to deduce building damages for a potential earthquake scenario (JICA and MoHA, 2002). The respective ground motion, seismicity, and fault model used can be found there. Unfortunately this study is the most recent published earthquake assessment for the Kathmandu Valley at this time. Out of the three different fault models used, the mid-Nepal earthquake with $M_{\mathrm{W}} 8.0$ would lead to MMI VIII within the valley (JICA and MoHA, 2002). This is seen as the "worst-case scenario" in terms of the modeled building damages and casualties. The SEDM building damage estimates were carried out in 2000-2002 and reflected the population in 2001 and the building stock from 1998. The first step in computing shelter demand for KMC was to update the 2001 population with the latest population data of the 2011 census. Due to the lack of detailed recent building data including building types, the population ratio $(r)$ serves as scaling factor to estimate building numbers for 2011 using the ward building inventory of 1998 according to Eq. (3):

$r=\frac{\operatorname{Pop}_{i}^{2011}}{\operatorname{Pop}_{i}^{1998}} \sim \frac{\mathrm{NB}^{2001}}{\mathrm{NB}^{1991}}$.

This simplification can be made since a comparison of the 1991 Housing Survey and the 2001 National Census revealed that the ratio of building stock to population has not changed significantly, and population growth between 2001 and 2011 was similar to the previous decade (CBS, 1995, 2002, 2012; NSET, 2012). Unfortunately there are no recent data on building stock composition available for KMC. This poses a serious limitation which we accounted for by assuming a linear increase without specifying details about replacements, upgrade, or deterioration of building structures during the last years. The Nepalese building code developed in 1994 was only in 2003 approved by the government and has never been implemented across the country. Most new buildings (private and public) do not comply with earthquake safety standards due to the lack of resources (enforcing governmental chapters, trained masons, financial resources, etc.) despite various efforts (Dixit, 2009). The actual composition of the building stock, therefore, had to be derived using the simplistic linear upscaling.

The need for public emergency shelter was computed based on a modified HAZUS methodology in a two-step approach. First, the number of displaced persons in each ward from the scenario earthquake are computed by assuming all occupants of heavily damaged buildings will be displaced. Additionally, even for building damages that may be moderate, some buildings may not be habitable, as lifeline breaks (e.g., water and electricity utilities) for an extended time often leads to people seeking shelter outside of their otherwise usable homes (e.g., Khazai et al., 2013). As of today, many people, especially in the core area of KMC, rely on water tankers servicing the area once a week or less (UNHABITAT, 2008). A high proportion of displaced persons can be assumed from partially damaged buildings since it is expected that secondary damages to water pipelines will affect $80 \%$ of water users (JICA and MoHA, 2002; cf. NRRC, 2013). Finally, partially damaged buildings of low-strength masonry made of fired bricks in mud mortar are treated as a special category. Even where partially damaged build- 
ings of this type could provide some shelter, past earthquake events show that aftershocks threaten to collapse these types of buildings and most survivors remain outside (Khazai and Hausler, 2005). Thus, the total number of displaced persons in $2011\left(\mathrm{DP}^{2011}\right)$ in $\mathrm{KMC}$ is given by the sum of displaced persons in each ward $i$ minus the casualties $(C)$ in ward $i$ as given by Eq. (4):

$$
\begin{aligned}
\mathrm{DP}^{2011} & =r \times\left(\sum_{i} \mathrm{HD} \_\mathrm{All}_{i}^{1998}+0.9 \sum_{i} \mathrm{PD}_{i} \mathrm{BM}_{i}^{1998}\right. \\
& \left.+0.8 \sum_{i} \mathrm{PD} \_ \text {nonBM }_{i}^{1998}-\sum_{i} C_{i}^{1998}\right) .
\end{aligned}
$$

According to Eq. (4), $100 \%$ of people from highly damaged buildings of all types (HD_All), 90\% of people from partially damaged brick in mud mortar buildings (PD_BM), and $80 \%$ of people from partially damaged buildings of all other types (PD_nonBM) will be displaced. While some displaced people will seek to use public shelter, experience in Nepal has shown that a fraction of the population will access other forms of shelter such as staying with friends and family or migrate to their original cities and villages. Likewise, a portion of the population will use their property or nearby areas as makeshift shelter sites (NSET, 2012). In a 2012 study on shelter response strategies by NSET it was determined that approximately $5 \%$ of the population will take shelter with their families and friends; approximately $5 \%$ will take shelter in damaged houses or self-managed temporary shelters nearby original houses; and approximately $2 \%$ will migrate to outside cities and villages (NSET, 2012). Two factors of residential urban fabric and migration to rural areas are thus considered here in determining a ward level distribution of populations seeking shelter in planned, public emergency shelter sites from the computed displaced population. First, the shelter-seeking population is obtained by reducing the total displaced population by 2,10 , or $15 \%$ depending on the corresponding levels of residential urban fabric (Table 2). The assumption is that in sparsely built urban areas where there is more outdoor space, a greater portion of the displaced population (up to $15 \%$ ) is likely to take up shelter on their own property or nearby areas rather than seeking shelter in the designated emergency shelter sites. In more dense urban areas, however, there is little or no space for self-managed shelter, thus only $2 \%$ of the displaced population may seek temporary shelter on non-designated open spaces. Next, the displaced population seeking shelter is further reduced by the internal migration rate from each ward based on the 2001 population census (Subedi, 2010). Here the assumption used is that $5 \%$ of the internal migrants in each ward will migrate to outside cities and villages instead of seeking public shelter.

The total displaced population within KMC derived from the modified ELE considering social factors and urban fabric settings is thus estimated as 406500 , while the total shelter demand is 342300 persons. Especially the core wards with their weak building structure and very high population densities are expected to have large numbers of casualties and a very high shelter demand.

The spatial representation used to calculate the $\mathrm{CAM}_{\mathrm{OS}}$ consists of building blocks and roads. A detailed road network provided by the Kathmandu Valley Development Authority (KVDA) was utilized. It consists of $1250 \mathrm{~km}$ roads classified into nine different types. The established topological network has 27724 nodes and 67118 edges. Additionally, 72783 building footprints based on Quickbird ${ }^{\circledR}$ satellite imagery from 2006 were included as demand points for all network-based measures. Within the core area, many buildings are not directly connected to the nearest road segment but through a sequential arrangement of courtyards and narrow passages. In extreme cases, several high-rise dwellings share a single courtyard with only one exit point towards other courtyards before even reaching a road or trail. Mapping of such narrow trails from satellite imagery is almost impossible. In these cases, courtyards were used as building block centroids with a higher weight and manually connected to the main road network. Shelter demand calculated on ward level in the first step had to be spatially disaggregated onto the building blocks. This is done by neglecting day- and nighttime population and occupancy rates for different building use. Additional knowledge on population dynamics, as in Freire and Aubrecht (2012) might, be beneficial for a more detailed study. Optionally, remote sensing has shown advantages in assessing the urban fabric and population distribution in larger agglomerations (e.g., Aubrecht et al., 2013; Kubanek et al., 2010; Taubenböck, 2008). Some key numbers and characteristics of the data used in this exemplary case study can be found in Table 3 .

Using this spatial representation of the urban environment, each building with its allocated weight corresponding to the number of persons seeking shelter is assigned to the nearest open space, taking into consideration network impedance and the sheltering capacity of that particular space. The location problem is solved so that (a) the nearest site is selected, (b) the overall weighted distances along the network for all buildings is minimized across the study area, and (c) no site remains unselected as long as there are buildings which are not served or the capacity is not reached.

One main obstacle to most network analysis methods are spatial boundary problems. The complete network and building database was available for inside KMC only. Thus people from outside KMC seeking shelter in any open space inside the municipal boundary or persons inside KMC seeking shelter outside the city boundaries were not considered. In special cases along the ring road, the identified open spaces consist mostly of two parts on both sides of the lane. To account for intrusion of people towards $\mathrm{KMC}$, we only used the ones towards KMC for the analysis. To the south, KMC borders the Bagmati river forming a physical barrier, which can only be traversed at a few bridges all considered not earth- 
Table 2. Shelter-seeking class definition.

\begin{tabular}{ll}
\hline Residential urban fabric & Shelter-seeking class \\
\hline Sparse density residential urban fabric & approx. 15\% of displaced population will not seek public shelter \\
Medium density residential urban fabric & approx. 10\% of displaced population will not seek public shelter \\
Dense to very dense residential urban fabric & approx. 2\% of displaced population will not seek public shelter \\
\hline
\end{tabular}

Table 3. Key characteristics of the used database.

\begin{tabular}{lr}
\hline Data & Value \\
\hline Number of open spaces inside KMC & 410 \\
Available open space & $2284731 \mathrm{~m}^{2}$ \\
Overall capacity & 253859 pers. \\
Shelter demand (ELE) & 342299 pers. \\
Served population (GIS) & 253806 pers. \\
Unserved population (GIS) & 88493 pers. \\
Number of buildings (GIS) & 72783 \\
Served buildings (GIS) & 54742 \\
Unserved buildings (GIS) & 18031 \\
Road network length (GIS) & $1250 \mathrm{~km}$ \\
Road network nodes (GIS) & 27294 \\
Road network edges (GIS) & 66576 \\
\hline
\end{tabular}

quake safe (JICA and MoHA, 2002; NSET and GeoHazards International, 1998). Hence for the chosen scenario, it can be assumed that from or to this side, no movement of population seeking shelter can be expected.

\section{Results}

As can be drawn from the raw numbers used for the analysis (Table 3), there is a lack of shelter space in terms of capacity. 342300 persons were estimated seeking public shelter within $\mathrm{KMC}$, using $9 \mathrm{~m}^{2}$ covered living space per person as a standard. Out of these, 253900 persons (74\%) can be accommodated using the above set restrictions in terms of distance and capacity.

Figure 3 shows the ranking results of the qualitative suitability criteria for the upper and lower 15 ranks, only displaying the cumulative value of SI. The OSSI ranking results are grouped in 0.2 ranges from Category A ( $>0.8$ to 1.0 , green) to Category $\mathrm{E}$ (below 0.2 , red). The most suitable open spaces in categories A and B add up to a total of 116 open spaces, which accounts for almost one-third of all open spaces $(28.3 \%)$. Categories D and E (not suitable) account for 50 open spaces $(12.2 \%)$. The distribution of OSSI values for all 410 open spaces is shown in Fig. 4.

Using the expert-based weighting scheme, the average contribution from each of the qualitative indicators for Category A is $21.1 \%$ for existent use, $12.0 \%$ for ownership, $2.1 \%$ for future plan, $17.9 \%$ for secondary hazard, $14.2 \%$ for pollution, $6.3 \%$ for water supply, $7.2 \%$ for electricity,

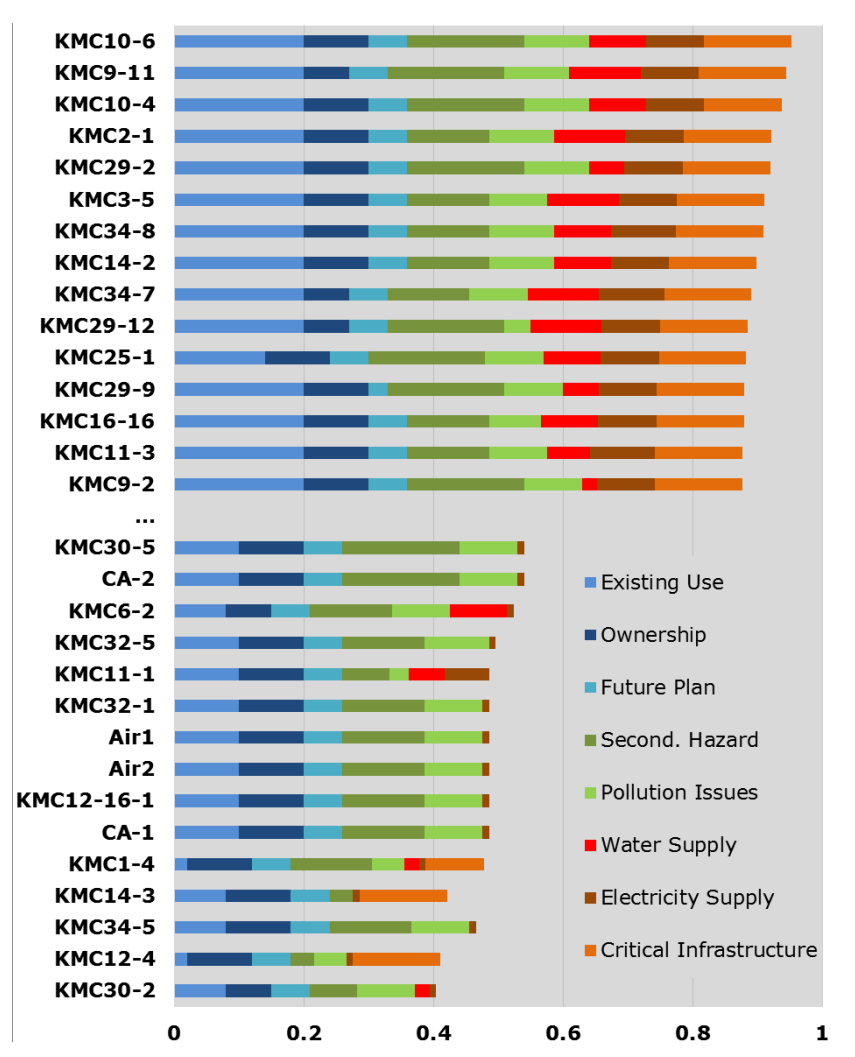

Figure 3. The first and last 15 open spaces ranked according to the suitability indicators.

and $19.2 \%$ for nearness to critical facilities. This is similar within all categories except Category $\mathrm{C}$, where existent use gains importance $(28.1 \%)$ and nearness to critical facilities drops $(6.4 \%)$. Existing future plans for the sites and nearness to critical facilities form an exception for Category A compared to the average of all categories (7.2 and $12.8 \%$, respectively). Water $(5.7 \%)$ and electricity supply $(5.4 \%)$ as well as nearness to critical facilities $(12.8 \%)$ all contribute on average across all categories (A to E) less than the applied weights $(11,10$, and $18 \%$, respectively).

The map representation of OSSI reveals some hot spots of shelter needs within KMC (Fig. 5). It shows the distribution of building blocks that can be served by one of the open spaces (light blue in the background) compared to the ones that remain unserved (light orange).

As a result, some wards are very well prepared in terms of suitable open space for shelter purposes, while others have a 


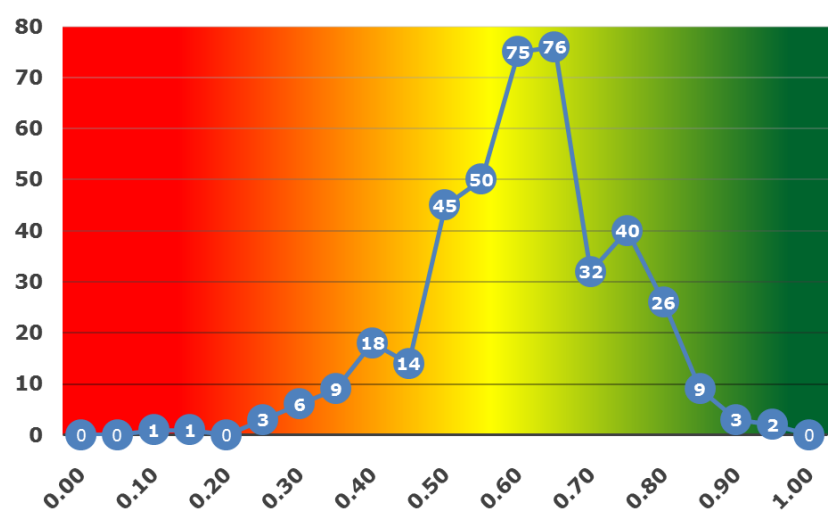

Figure 4. Distribution of OSSI values for all open spaces.

lack in terms of either the capacity of the sites or their suitability. Especially to the west of the core wards, where highrise dwellings and extremely dense areas are located, shelter deficits can be observed. Clusters of well-connected and high-capacity sites, e.g., around Pashupati Temple area in the east, are important in reducing people's shelter vulnerability.

\section{Discussion and conclusion}

In this paper we analyze 410 open spaces identified as emergency shelter sites within KMC in terms of their suitability for shelter. Four aspects are evaluated: shelter implementation issues, environmental considerations, availability of basic utilities, and the capacity-based coverage analysis. The methodology offers a straightforward way to identify hotspots in urban settings in terms of areas under-served by open spaces that can be used for emergency immediately after an earthquake. It combines an approach to classify and rank depth-qualitative information on the suitability of open spaces for emergency shelter available through site visits with knowledge from local experts of quantitative information on shelter capacity, derived from shelter need calculations using earthquake risk analysis and site accessibility from a GIS-based network accessibility model.

On the demand side, a comprehensive database of available candidate sites is needed, spatially covering the study area. Such data might be available through local agencies as in the Kathmandu case but for some areas need to be compiled from other sources or researched. The $\mathrm{CAM}_{\mathrm{OS}}$ at the same time relies on fully functional and topologically correct road network. As such the proposed methodology depends on detailed spatial data which might not be available in some places. However, advancing tools for deriving data from remote sensing and/or VGI data (e.g., OpenStreetMap) offer huge opportunities for acquiring data. Taubenböck and Strunz (2013) provide a conceptual framework for some of the pertinent questions of earthquake risk reduction using remote sensing. Thus high-resolution satellite imagery together

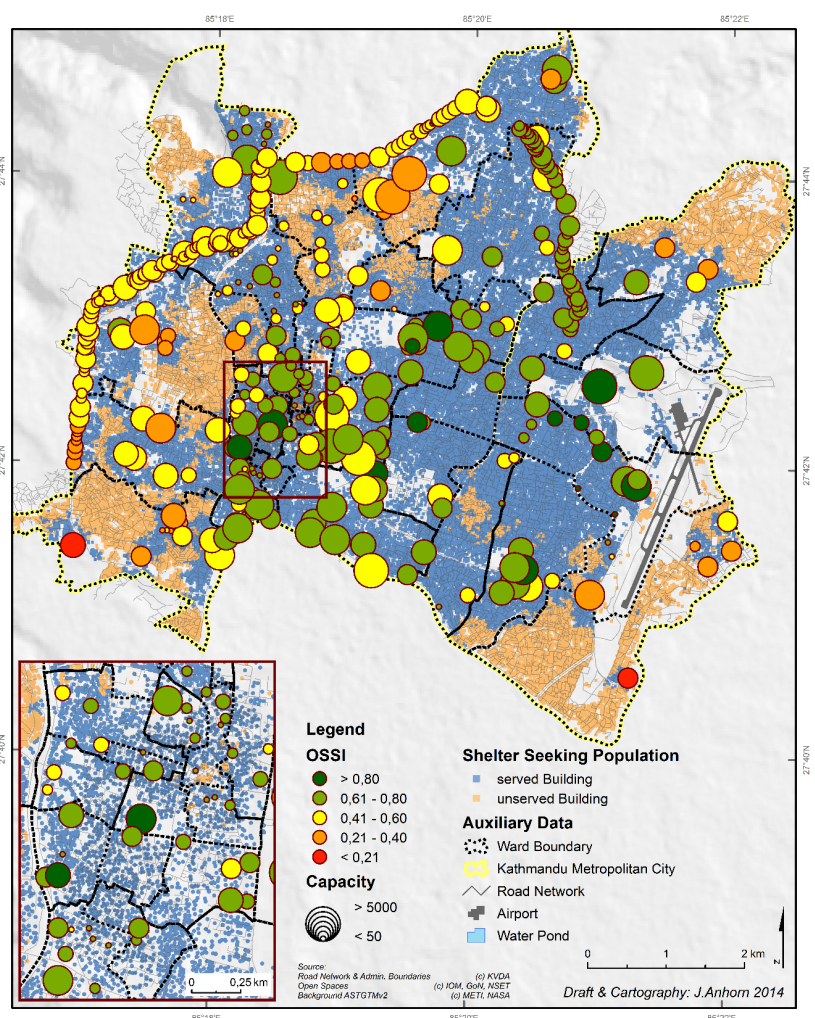

Figure 5. Spatial representation of the Open Space Suitability Index for Kathmandu Metropolitan City.

with improved semi-automatic (object-oriented) feature extraction tools offer wide applications (e.g., Wieland et al., 2012). Likewise, local governments often do see a benefit in establishing and maintaining spatial databases which then can be used firsthand. In this Kathmandu test case, the data sets used (road network and building footprints) were readily available through official governmental units (e.g., KVDA, Dept. of Survey) and only minor corrections had to be conducted. Hence not all earthquake-prone urban areas have to be considered data sparse.

The selection of criteria for qualitative evaluation of open space suitability is based on thorough literature review and the latest design standards (e.g., FEMA, 2007; SPHERE Project, 2011). However, the criteria, sub-criteria, and indicators used can be taken as a model and customized to fit the particular needs of a different context. Shelter suitability is calculated for this case study as a function of immediate shelter needs derived from structural earthquake damage, availability of critical services, and accessibility. The concept behind OSSI could be used for many other hazards, if shelter needs and suitability criteria (including the proposed scoring and weighting) as well as the time horizon are contextualized accordingly. As one limitation, this paper focuses on immediate shelter suitability and not reconstruction of settlements, which would most likely need different 
qualitative parameters. While the open space suitability indicators were developed to be transferable to other urban settings, they were arrived at and influenced to some extent by the Kathmandu context. We used an expert-based approach to identify the most important criteria and evaluated the importance with the help of group discussions. Besides multifaceted objectives of different stakeholders and experts, data availability also shapes the selection of certain criteria. Additionally, Chien et al. (2002), for example, found that climate and weather conditions in different seasons influence peoples shelter-seeking behavior. This and other temporally set factors were not taken into consideration so far. We have considered flood, landslide, and fire hazard as part of the suitability indicators under the environmental considerations category (see Table 1). By considering at least the distance to critical sources of fire like gas and petrol stations, we aim to avoid exposing people in earthquake shelter to secondary threats. Nevertheless, emergency response services (e.g., fire brigade) in Kathmandu are known to be very limited in personnel and equipment. We would like to highlight the necessity to use the most recent available hazard information also considering cascading effects to avoid putting people at risk in designated shelter areas. In general the indicator-based methodology allows for any incorporation of more detailed data (e.g., from flood hazard models) and is transferable to other hazards with respect to shelter placement problems.

The proposed methodology to investigate the suitability of open spaces poses some limitations due to data constraints and therefore provides a methodological framework with potential for further enhancement. Some suggestions are given here with respect to the case study in Kathmandu and future transfer of the method to other cases: (a) population distribution usually varies across time and space within an urban area, so we recommend adjusting this parameter to the best available model (e.g., Aubrecht et al., 2013). (b) Earthquake risk scenarios highly depend on detailed seismological studies (i.e., microzonation) as well as information about the fragility of elements at risk (critical infrastructure, buildings, etc.). In this case study we only considered one so-called worst-case scenario. More ideally, cascading secondary effects as well as multiple scenarios should be integrated. However, the number of these scenarios must then be reduced to become manageable for shelter planning processes. (c) The proposed methodology relies on detailed geospatial data which are prone to be outdated, fragmented, and limited in detail. Users have to identify the most comprehensive data set or make use of promising data capturing tools available (e.g., Pittore and Wieland, 2013; Wieland et al., 2012). (d) The road network is considered a fully functional relational network, the potential failure/disruption of accessibility due to debris cover or damages. No actual damage of the road network is accounted for in the capacitated accessibility measure so far. Modeling road blockage due to debris and damages, as well as accessibility of building blocks in postdisaster situations proposed by Caiado et al. (2011, 2012),
Chang et al. (2012), or Franchin et al. (2006), or incorporating the robustness and redundancy of street networks into the overall suitability might advance the proposed method. (e) The selected qualitative evaluation criteria their scoring and weighting should always be based on local experts, taking into account contextualized conditions. This also applies to the potentially necessary incorporation of additional criteria. (f) People's needs and preferences for selecting shelter places change over time. We only considered a limited number of factors influencing suitability for immediate shelter, taking a mixed planner's and inhabitant's position in evaluating them. Medium- and long-term shelter may need different factors. The adjustment to such dynamic circumstances is what we understand as contextualization of models and is not yet part of the KMC case study.

The hotspot map that was derived according to the OSSI rankings of open spaces can guide decision-makers to develop strategies and earthquake contingency plans for shelter placement. The analysis specifically addresses the emergency shelter logistics and resource allocation problem: where do we expect shelter deficits and where do we need to improve site suitability or identify alternative sites.

It has been argued that optimal site selection for emergency planning needs to consider two main aspects: first, a sufficient quantity of accessible shelter area and second, site quality in terms of people-centered shelter needs. An indicator-based methodology for combining both the qualitative suitability criteria and the quantitative shelter needs and site accessibility measured has been presented through the Open Space Suitability Index. The potential of such methods lies in its applicability to further areas, variable types of candidate sites, and/or changing time frames of sheltering. Therefore, the initial weights and scores of the suitability index need to be contextualized according to the specific purpose and possibly different hazard(s). One main recommendation is to engage local experts and decision-makers in a participatory approach in the selection and weighting process to achieve consensus about the structure and perceived importance of the different indicators. To this end the approach outlined here and the assumptions made are based on consultations with local experts at NSET and developed as a preparedness tool for emergency shelter allocation in KMC. Further studies are needed to test these assumptions both for shelter suitability and shelter demand and to understand better patterns and behavior of displaced populations in seeking public shelter. 
Acknowledgements. This study is part of the "Integrated Earthquake Risk Assessment for the Himalayan Region” project (IERAHimal), funded by the Heidelberg-Karlsruhe Research Partnership (HEiKA). We acknowledge financial support by Deutsche Forschungsgemeinschaft and Ruprecht-Karls-Universität Heidelberg within the funding programme Open Access Publishing.

The authors would like to acknowledge Julia Schaper for her input in the development of this paper. The authors also thank the National Society for Earthquake Technology, Nepal, for their great support, provision of data, and insight. We would especially like to thank Ganesh K. Jimee, Amod M. Dixit, Surya N. Shresta, Ramesh Guragain, and Gopi K. Basyal for their insights and expert advice.

Edited by: F. Guzzetti

Reviewed by: N. Kerle and two anonymous referees

\section{References}

ABAG: Shaken awake! Estimates of uninhabitable dwelling units and peak shelter populations in future earthquakes affecting the San Francisco Bay region, Association of Bay Area Governments, Oakland, 1996.

Aubrecht, C., Özceylan, D., Steinnocher, K., and Freire, S.: Multi-level geospatial modeling of human exposure patterns and vulnerability indicators, Nat. Hazards, 68, 147-163, doi:10.1007/s11069-012-0389-9, 2013.

Balcik, B., Beamon, B. M., Krejci, C. C., Muramatsu, K. M., and Ramirez, M.: Coordination in humanitarian relief chains: Practices, challenges and opportunities, Int. J. Prod. Econ., 126, 2234, doi:10.1016/j.ijpe.2009.09.008, 2010.

Bharosa, N., Lee, J., and Janssen, M.: Challenges and obstacles in sharing and coordinating information during multi-agency disaster response: Propositions from field exercises, Inf. Syst. Front., 12, 49-65, doi:10.1007/s10796-009-9174-z, 2010.

Caiado, G., Macário, R., and Oliveira, C. S.: A New Paradigm in Urban Road Network Seismic Vulnerability: From a Linkby-link Structural Approach to an Integrated Functional Assessment, edited by: Santos, M. A., Sousa, L., and Portela, E., National Civil Engineering Laboratory, Lisbon, available at: http://www.iscramlive.org/ISCRAM2011/proceedings/ papers/221.pdf (last access: 9 July 2014), 2011.

Caiado, G., Oliveira, C. S., Ferreira, M. A., and Sá, F.: Assessing Urban Road Network Seismic Vulnerability: An Integrated Approach, Indian Institute of Technology, Lisbon, available at: http://www.iitk.ac.in/nicee/wcee/article/WCEE2012_ 1105.pdf (last access: 9 July 2014), 2012.

Cavalieri, F., Franchin, P., Gehl, P., and Khazai, B.: Quantitative assessment of social losses based on physical damage and interaction with infrastructural systems, Earthq. Eng. Struct. Dyn., 41, 1569-1589, doi:10.1002/eqe.2220, 2012.

CBS (Ed.): National Population Census 1991 (National Report), 2nd Edn., Government of Nepal, National Planning Commission Secretariat, Central Bureau of Statistics, Kathmandu, 1995.

CBS (Ed.): Population Census 2001 (National Report), His Majesty's Government of Nepal, National Planning Commission, Central Bureau of Statistics, Kathmandu, 2002.
CBS (Ed.): National Population and Housing Census 2011: National Report, Government of Nepal, National Planning Commission Secretariat, Central Bureau of Statistics, Kathmandu, 2012.

Chakraborty, J., Tobin, G., and Montz, B.: Population Evacuation: Assessing Spatial Variability in Geophysical Risk and Social Vulnerability to Natural Hazards, Nat. Hazards Rev., 6, 23-33, doi:10.1061/(ASCE)1527-6988(2005)6:1(23), 2005.

Chandler, P. J.: Environmental Factors Influencing the Siting of Temporary Housing in Orleans Parish, Master of Science, Louisiana State University, Department of Environmental Studies, Louisiana, 2007.

Chang, L., Elnashai, A. S., and Spencer, B. F.: Post-earthquake modelling of transportation networks, Struct. Infrastruct. Eng., 8, 893-911, doi:10.1080/15732479.2011.574810, 2012.

Chang, S. E. and Chamberlin, C.: Assessing the role of lifeline systems in community disaster resilience, Res. Prog. Accompl., 2003-2004, 87-94, 2003.

Chang, S., Pasion, C., Yavari, S., and Elwood, K.: Social Impacts of Lifeline Losses: Modeling Displaced Populations and Health Care Functionality, in: Lifeline Earthquake Engineering in a Multihazard Environment, edited by: Tang, A. K. K. and Werner, S., 563-572, American Society of Civil Engineers, Oakland, 2009.

Chien, S., Chen, L., Chang, S., Chiu, G., and Chu, C.: Development of an after earthquake disaster shelter evaluation model, J. Chin. Inst. Eng., 25, 591-596, doi:10.1080/02533839.2002.9670733, 2002.

Chou, J.-S., Ou, Y.-C., Cheng, M.-Y., Cheng, M.-Y., and Lee, C.M.: Emergency shelter capacity estimation by earthquake damage analysis, Nat. Hazards, 65, 2031-2061, doi:10.1007/s11069012-0461-5, 2013.

Chu, J. Y. and Su, Y. P.: Comprehensive Evaluation Index System in the Application for Earthquake Emergency Shelter Site, Adv. Mater. Res., 156-157, 79-83, doi:10.4028/www.scientific.net/AMR.156-157.79, 2011.

Coburn, A. and Spence, R.: Earthquake Risk Modelling, in Earthquake Protection, 311-352, John Wiley \& Sons Ltd, Chichester, doi:10.1002/0470855185.ch9, 2006.

Coburn, A. W., Spence, R. J. S., and Pomonis, A.: Factors determining human casualty levels in earthquakes: Mortality prediction in building collapse, in: Proceedings of the Tenth World Conference Earthquake Engineering, Vol. 10, 5989-5994, A.A. Balkema, Rotterdam, 1992.

Cova, T. J. and Church, R. L.: Modelling community evacuation vulnerability using GIS, Int. J. Geogr. Inf. Sci., 11, 763-784, doi:10.1080/136588197242077, 1997.

Cova, T. J. and Johnson, J. P.: Microsimulation of neighborhood evacuations in the urban - wildland interface, Environ. Plan. A, 34, 2211-2229, doi:10.1068/a34251, 2002.

Crucitti, P., Latora, V., and Porta, S.: Centrality measures in spatial networks of urban streets, Phys. Rev. E, 73, 036125, doi:10.1103/PhysRevE.73.036125, 2006.

Daley, W. R., Karpati, A,. and Sheik, M.: Needs Assessment of the Displaced Population Following the August 1999 Earthquake in Turkey, Disasters, 25, 67-75, doi:10.1111/1467-7717.00162, 2001.

Daniell, J. E., Khazai, B., Wenzel, F., and Vervaeck, A.: The CATDAT damaging earthquakes database, Nat. Hazards Earth Syst. Sci., 11, 2235-2251, doi:10.5194/nhess-11-2235-2011, 2011. 
Da Silva, J.: Quality and standards in post-disaster shelter, Struct. Eng., 85, 25-32, 2007.

Dixit, A. M.: Challenges of Building Code Implementation in Nepal, in: From Code to Practice: Challenges for Building Code Implementation And the Further Direction of Housing Earthquake Safety, edited by: Ando, S., Subedi, J. K., and Nakamura, H., 61-66, UNCRD, available at: http://www.preventionweb.net/ files/10591_HESITokyoPapers.pdf (last access: 13 May 2014), 2009.

Dixit, A., Dwelley-Samant, L., Nakarmi, M., Pradhanang, S. B., and Tucker, B. E.: The Kathmandu Valley Earthquake Risk Management Project: An Evaluation, in: Proceedings, 12th World Conference on Earthquake Engineering, Auckland, New Zealand, available at: http://www.iitk.ac.in/nicee/wcee/article/ 0788.pdf (last access: 28 August 2013), 2000.

Donohou, C.: Strategic Planning for Post-Earthquake Temporary Housing: Best Practices, edited by: Hall, S. and Hapeman, K., Humanit, Briefs Spanning Field Relief Aid Dev., 16, 2012.

EMI: Risk-Sensitive Land Use Plan: Kathmandu Metropolitan City, Nepal, Earthquakes and Megacity Initiative (EMI), Manila, available at: http://www.preventionweb.net (last access: 3 June 2014), 2010.

ESRI: ArcGIS Help 10.1, ArcGIS Help 101, available at: http:// resources.arcgis.com/en/help/main/10.1/index.html, last access: 21 August 2013.

Félix, D., Branco, J. M., and Feio, A.: Temporary housing after disasters: A state of the art survey, Habitat Int., 40, 136-141, doi:10.1016/j.habitatint.2013.03.006, 2013.

FEMA: HAZUS99 Technical Manual: Earthquake Model, FEMA, Washington, D.C., 1999.

FEMA: Emergency temporary group housing site selection guidelines - Minimizing environmental/historic/safety problems, available at: http://www.fema.gov (last access: 13 August 2013), 2007

FEMA: HAZUS-MH 2.1 Technical Manual: Earthquake Model, available at: http://www.fema.gov (last access: 14 August 2013), 2011.

Franchin, P., Lupoi, A., and Pinto, P. E.: On the Role of Road Networks in Reducing Human Losses After Earthquakes, J. Earthq. Eng., 10, 195-206, doi:10.1080/13632460609350593, 2006.

Freire, S. and Aubrecht, C.: Integrating population dynamics into mapping human exposure to seismic hazard, Nat. Hazards Earth Syst. Sci., 12, 3533-3543, doi:10.5194/nhess-12-3533-2012, 2012.

Gall, M.: Where to Go? Strategic Modelling of Access to Emergency Shelters in Mozambique, Disasters, 28, 82-97, doi:10.1111/j.0361-3666.2004.00244.x, 2004.

Global Communities: Shelter and Settlements: Post-Disaster Response in Urban Environments, available at: http://www. globalcommunities.org/node/37242 (last access: 8 August 2013), 2012.

Guragain, R., Jimee, G. K., and Dixit, A. M.: Earthquake Awareness and Effective Planning Through Participatory Risk Assessment: An Experience from Nepal, in: Proceedings of 14th World Conference on Earthquake Engineering, 12-17, NICEE, Beijing, available at: http://www.iitk.ac.in/nicee/wcee/article/14_ 07-0086.pdf (last access: 28 August 2013), 2008.

Gutschow, N. and Kreutzmann, H.: Handlung schlägt Plan, Geogr. Rundsch., 4, 42-49, 2012.
Haack, B. N. and Rafter, A.: Urban growth analysis and modeling in the Kathmandu Valley, Nepal, Habitat Int., 30, 1056-1065, doi:10.1016/j.habitatint.2005.12.001, 2006.

Harrald, B. F. and al Hajj, S. F.: Estimates for Demand for Mass Care Services in Future Earthquakes Affecting the San Francisco Bay Region, George Washington University for The American Red Cross, 1992.

Indriasari, V., Mahmud, A. R., Ahmad, N., and Shariff, A. R. M.: Maximal service area problem for optimal siting of emergency facilities, Int. J. Geogr. Inf. Sci., 24, 213-230, doi:10.1080/13658810802549162, 2010.

IOM and GoN: Report on Identification of Open Spaces for Humanitarian Purposes in Kathmandu Valley, International Organization for Migration, Kathmandu, 2012.

JICA and MoHA: The Study on Earthquake Disaster Mitigation in the Kathmandu Valley, Kingdom of Nepal, Final Report, Japan International Cooperation Agency, Kathmandu, 2002.

Johnson, C.: Strategic planning for post-disaster temporary housing, Disasters, 31, 435-458, doi:10.1111/j.1467-7717.2007.01018.x, 2007.

Johnson, C.: Planning for temporary housing, in: Rebuilding After Disasters?: From Emergency to Sustainability, edited by: Lizarralde, G., Johnson, C., and Davidson, C. H., 70-87, Taylor \& Francis, Independence, 2009.

Kar, B. and Hodgson, M. E.: A GIS-Based Model to Determine Site Suitability of Emergency Evacuation Shelters, Trans. GIS, 12, 227-248, doi:10.1111/j.1467-9671.2008.01097.x, 2008.

Khazai, B. and Hausler, E.: Intermediate Shelters in Bam and Permanent Shelter Reconstruction in Villages Following the 2003 Bam, Iran, Earthquake, Earthq. Spectra, 21, 487-511, doi:10.1193/1.2098907, 2005.

Khazai, B., Daniell, J. E., and Wenzel, F.: The March 2011 Japan Earthquake: Analysis of Losses, Impacts, and Implications for the Understanding of Risks Posed by Extreme Events, Tech.Teor. Prax., 20, 22-33, 2011.

Khazai, B., Daniell, J. E., Franchin, P., Cavalieri, F., Vangelsten, B. V., Lervolino, L., and Esposito, S.: A New Approach to Modeling Post-Earthquake Shelter Demand: Integrating Social Vulnerability in Systemic Seismic Vulnerability Analysis, in: Proceedings of the 15th World Conference on Earthquake Engineering, 21052115, National Information Centre of Earthquake Engineering, Lisbon, 2012.

Khazai, B., Argyroudis, S., Hancilar, U., Taucer, F., and Kakderi, K.: Guidelines for the consideration of socio-economic impacts in seismic risk analysis, SYNER-G Reference Report 5, European Commission Joint Research Centre, Institute for the Protection and Security of the Citizen, Ispra, available at: http: //www.syner-g.eu (last access: 3 June 2014), 2013.

Khazai, B., Daniell, J. E., Düzgün, S., Kunz-Platt, T., and Wenzel, F.: Framework for Systemic Socio-Economic Vulnerability and Loss Assessment, in: SYNER-G: Systemic Seismic Vulnerability and Risk Assessment of Complex Urban, Utility, Liefeline Systems and Critical Facilities, edited by: Pitilakis, K., Franchin, P., Khazai, B., and Wenzel, H., Springer, Heidelberg, 2014.

Kongsomsaksakul, S., Chen, A., and Yang, C.: Shelter LocationAllocation Model for Flood Evacuation Planning, J. East. Asia Soc. Transp. Stud., 6, 4237-4252, 2005.

Kubanek, J., Nolte, E.-M., Taubenböck, H., Kappas, M., and Wenzel, F.: Modelling of population dynamics: GIS versus Remote 
sensing - a case study for Istanbul, in: Proceedings of TIEMS, 1-10, Beijing, China, 2010.

Lizarralde, G., Johnson, C., and Davidson, C. H. (Eds.): Rebuilding After Disasters: From Emergency to Sustainability, Taylor \& Francis, Independence, 2009.

McEntire, D. A.: Disaster response and recovery: strategies and tactics for resilience, Wiley, Hoboken, NJ, 2007.

Neis, P. and Zielstra, D.: Recent Developments and Future Trends in Volunteered Geographic Information Research: The Case of OpenStreetMap, Future Internet, 6, 76-106, doi:10.3390/fi6010076, 2014.

Neis, P., Singler, P., and Zipf, A.: Collaborative mapping and Emergency Routing for Disaster Logistics-Case studies from the Haiti earthquake and the UN portal for Afrika, in: Proceedings of the Geoinformatics Forum Salzburg, Vol. 10, edited by: Car, A., Griesebner, G., and Strobl, J., 239-248, Wichmann, Salzburg, available at: http://koenigstuhl.geog.uni-heidelberg.de/publications/2010/ Neis/un-osm-emergency-routing.gi-forum2010.full.pdf (last access: 21 August 2013), 2010.

NRRC: Earthquake Scenario of Kathmandu Valley, Interview with Moira Reddick (Video), available at: http://youtu.be/ HN3T7fYVJYk, last access: 12 August 2013.

NSET: Shelter Response Strategy and Plan for Earthquake Disasters For Kathmandu Valley, Nepal, Draft Report, National Society for Earthquake Technology - Nepal, Kathmandu, 2010.

NSET: Shelter Response Strategy and Plan for Earthquake Disasters For Kathmandu Valley, Nepal, Final Report, National Society for Earthquake Technology - Nepal, Kathmandu, 2012.

NSET and GeoHazards International (Eds.): The Kathmandu Valley Earthquake Risk Management Action Plan, National Society for Earthquake Technology - Nepal, Kathmandu, 1998.

Perry, R. W.: Evacuation decision-making in natural disasters, Mass Emerg., 4, 25-38, 1979.

Perry, R. W. and Green, M. R.: The Role of Ethnicity in the Emergency Decision-Making Process, Sociol. Inq., 52, 306-334, doi:10.1111/j.1475-682X.1982.tb01257.x, 1982.

Pittore, M. and Wieland, M.: Toward a rapid probabilistic seismic vulnerability assessment using satellite and ground-based remote sensing, Nat. Hazards, 68, 115-145, doi:10.1007/s11069-0120475-z, 2013.

Porta, S., Crucitti, P., and Latora, V.: The network analysis of urban streets: A dual approach, Phys. Stat. Mech. Its Appl., 369, 853866, doi:10.1016/j.physa.2005.12.063, 2006a.

Porta, S., Crucitti, P., and Latora, V.: The network analysis of urban streets: A primal approach, Environ. Plan. B, 33, 705-725, doi:10.1068/b32045, 2006b.

Quarantelli, E. L.: Patterns of sheltering and housing in US disasters, Disaster Prev. Manag., 4, 43-53, doi:10.1108/09653569510088069, 1995.

Rawls, C. G. and Turnquist, M. A.: Pre-positioning of emergency supplies for disaster response, Transp. Res. Part B Methodol., 44, 521-534, doi:10.1016/j.trb.2009.08.003, 2010.

Riad, J. K., Norris, F. H., and Ruback, R. B.: Predicting Evacuation in Two Major Disasters: Risk Perception, Social Influence, and Access to Resources, J. Appl. Soc. Psychol., 29, 918-934, doi:10.1111/j.1559-1816.1999.tb00132.x, 1999.
Ritchie, L. A. and Tierney, K.: Temporary Housing Planning and Early Implementation in the 12 January 2010 Haiti Earthquake, Earthq. Spectra, 27, 487-507, doi:10.1193/1.3637637, 2011.

Samardjieva, E. and Badal, J.: Estimation of the Expected Number of Casualties Caused by Strong Earthquakes, Bull. Seismol. Soc. Am., 92, 2310-2322, doi:10.1785/0120010112, 2002.

Sevtsuk, A. and Mekonnen, M.: Urban network analysis, Rev. Int. Géomatique, 22, 287-305, doi:10.3166/RIG.22.287-305, 2012.

SPHERE Project (Ed.): SPHERE Handbook: Humanitarian Charter and Minimum Standards in Disaster Response, 3rd Edn., SPHERE Project, Bourton on Dunsmore, available at: www. sphereproject.org (last access: 17 July 2013), 2011.

Subedi, B. P.: Ethnic/caste diversification in Kathmandu metropolitan: Changing social landscape of a capital city, J. Geogr. Reg. Plan., 3, 185-199, 2010.

Tai, C.-A., Lee, Y.-L., and Lin, C.-Y.: Urban Disaster Prevention Shelter Location and Evacuation Behavior Analysis, J. Asian Archit. Build. Eng., 9, 215-220, doi:10.3130/jaabe.9.215, 2010.

Taubenböck, H.: Vulnerabilitätsabschätzung der erdbebengefährdeten Megacity Istanbul mit Methoden der Fernerkundung, Dissertation, Universität Würzburg, Philosophische Fakultät I, Institut für Geographie und Geologie, Würzburg, 4 July, available at: http://opus.bibliothek.uni-wuerzburg.de/volltexte/2008/2804/ (last access: 15 April 2012), 2008.

Taubenböck, H. and Strunz, G.: Widening a narrow road: remote sensing contributing to the multifaceted problem of earthquake risk reduction, Nat. Hazards, 68, 1-5, doi:10.1007/s11069-0130604-3, 2013.

Thapa, R. B. and Murayama, Y.: Examining Spatiotemporal Urbanization Patterns in Kathmandu Valley, Nepal: Remote Sensing and Spatial Metrics Approaches, Remote Sens., 1, 534-556, doi:10.3390/rs1030534, 2009.

Thapa, R. B., Murayama, Y., and Ale, S.: City Profile Kathmandu, Cities, 25, 45-57, doi:10.1016/j.cities.2007.10.001, 2008.

Tierney, K. J., Lindell, M. K., and Perry, R. W.: Facing the Unexpected: Disaster Preparedness and Response in the United States, The National Academies Press, Washington, D.C., 2001.

Toregas, C., Swain, R., ReVelle, C., and Bergman, L.: The Location of Emergency Service Facilities, Oper. Res., 19, 1363-1373, doi:10.1287/opre.19.6.1363, 1971.

UN DESA: World Urbanization Prospects The 2011 Revision, available at: http://esa.un.org/unup/index.html (last access: 12 August 2013), 2012.

UNDRO (Ed.): Shelter after disaster: guidelines for assistance, United Nations, available at: http://sheltercentre.org (last access: 5 August 2013), 1982.

UN-HABITAT: Water Movements in Patan with Reference to Traditional Stone Spouts, UN-HABITAT, Kathmandu, 2008.

UN ISDR and UN OCHA: Disaster preparedness for effective response: guidance and indicator package for implementing priority five of the Hyogo Framework, United Nations, New York, Geneva, 2008.

UN OCHA, DFID and Shelter Centre (Eds.): Shelter after disaster: strategies for transitional settlement and reconstruction, United Nations, available at: http://sheltercentre.org (last access: $5 \mathrm{Au}-$ gust 2013), 2010.

Upreti, N.: Comparative Analysis of Levels of Earthquake Risk Perception in Kathmandu Valley in 1998 and 2009, Master's Thesis, Sikkim Manipal University, New Delhi, 2009. 
Weiser, A. and Zipf, A.: Web Service Orchestration of OGC Web Services for Disaster Management, in: Geomatics Solutions for Disaster Management, edited by: Li, J., Zlatanova, S., and Fabbri, A. G., 239-254, Springer Berlin Heidelberg, 2007.

Wieland, M., Pittore, M., Parolai, S., Zschau, J., Moldobekov, B., and Begaliev, U.: Estimating building inventory for rapid seismic vulnerability assessment: Towards an integrated approach based on multi-source imaging, Soil Dyn. Earthq. Eng., 36, 7083, doi:10.1016/j.soildyn.2012.01.003, 2012.
Wright, K. and Johnston, D.: Post-earthquake Sheltering Needs: How Loss of Structures and Services Affects Decision Making for Evacuation, in: Proceedings NZSEE Conference, Vol. Session 7B, Paper 31, New Zealand Society for Earthquake Engineering Inc., Wellington, available at: http://www.nzsee.org.nz/ db/2010/ (last access: 3 June 2014), 2010. 